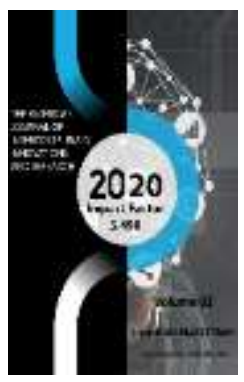

Journal Website: http://usajournalshub.c om/index,php/tajiir

Copyright: Original content from this work may be used under the terms of the creative commons attributes 4.0 licence.

\section{Photosynthetic Apparatus Of Cotton Leaf: Activity Under Harmful Factors And Inductors}

\author{
Sadbarkhon Abdukarimovna Mavlanova \\ Candidate Of Biological Sciences, Associate Professor, Department Of Fundamentals of \\ Physiology And Valeology Namangan State University, Uzbekistan
}

Azamat Moydinjanovich Ismatov

Doctor Of Philosophy In Biological Sciences, Department Of Ecology, Namangan State University, Uzbekistan

\title{
ABSTRACT
}

The article deals with the effect of a typical representative of sucking pests on the photosynthetic apparatus of the plant - the mite, and the effectiveness of measuring photosynthetic activity using a highly sensitive fluorescent method. Alternatively, photosynthetic apparatus activity was measured using the fluorescent method, and it was used to assess the degree of pest infestation of the plant, especially mites, and to determine the plant's resistance after red light treatment. When damaged by mites, the long-wave native forms of cotton chlorophyll are disrupted and the electron-transport chain of the photosynthetic apparatus is blocked. As a result of QN treatment of seeds, the distribution of algae in plants decreases, while the activity of photosynthetic apparatus, on the contrary, increases. This means that phyto-chrome photo conversion has a specific effect on the photosynthetic apparatus.

\section{KEYWORDS}

Photosynthesis, fluorescent method, fluorescence, light-collecting complex, luminescence, electrontransport chain, fluorescence induction, spectral-kinetic parameters.

\section{INTRODUCTION}

It is known that one of the integral indicators of the general condition of the plant is the activity of the photosynthetic apparatus in them: the better the condition of the plant, the higher the photosynthetic activity in them $[1$, p. 176]. 
Logically, the level of activity of the photosynthetic apparatus in plants decreases when pests and insects spread and are damaged as a result. This is confirmed by the data in the literature. For example, a typical representative of sucking pests in plants - the level of photosynthesis in the leaves decreases during the initial stage of the spread of mites [2, p. 43].

The damage of mites, unlike other rodent pests, is mainly limited to mechanical damage to the tissues of plants. The whitewash injects the suction-oral apparatus into the plant's covering tissue, sends digestive enzymes to it, and absorbs the liquid food processed outside the gut from the plant. The mechanical effect of the pest on the damaged plant is less noticeable. However, the physiologically active substances that send them to the plant disrupt physiological and biochemical processes (water metabolism, photosynthesis, hormonal regulation, etc.). Perhaps the hydrolysis products of biopolymers that are partially increased and not used by the pest can also alter plant development. Metabolic disorders eventually adversely affect the growth and development of the plant organism [2, p. 43].

\section{THE MAIN FINDINGS AND RESULTS}

Measurement of photosynthetic activity using a highly sensitive fluorescent method is effective [3, p. 188; 4, 40]. Therefore, we measured the activity of the photosynthetic apparatus using the fluorescent method and used it to assess the degree of infestation of the plant with pests, especially mites, and to determine the resistance of the plant after treatment with red light.

We used the ratio of fluorescence intensity (1690/1732) at 2 wavelengths as the indicator describing the changes in fluorescence, as well as the ratio of the maximum fluorescence intensity ( $\mathrm{Fp}$ ) to the stationary fluorescence intensity index (Fo) ( $\mathrm{P}=\mathrm{Fp}-\mathrm{Fo} / \mathrm{Fp}$ ). Simply put, the smaller the $1690 / 1732$ ratio and the larger the Fp-Fo/Fp, the higher the PHA activity.

In the first step, we learned that the LIF parameters depend on the number of mites on the cotton leaf. To do this, we selected three groups of cotton leaves with different levels of mites: 1 - control, insect-free and no signs of damage to the plant, 2 - moderately widespread pests, signs of damage were less noticeable and 3 - strongly distributed pests, signs of damage were clearly visible leaves.

The results show that the $1690 / 1732$ ratio also increases as the plant is damaged (Table 1 ).

This figure appears to have increased by $28 \%$ when the average number of insects in the plant. As the number of algae in the plant increases, the $1690 / 1732$ ratio increases almost linearly, reaching a maximum of 1.5 times that of the control.

The changes in the Ib9o / 1732 ratio associated with the increase in fluorescence intensity at $690 \mathrm{~nm}$ we observed are due to the disruption of the electron transport chain (ETC) in the sections between I (FS I) and II photosystem (FS II). As a result, FS II is restored, which helps the energy of the excited molecules to be used for luminescence. A decrease in the peak intensity belonging to I FS at $732 \mathrm{~nm}$ relative to the control indicates a decrease in its amount as a result of I FS distortion or a violation of the phosphorylation of the lightcollecting complex (LFC). Such a disruption can occur as a result of the effect of protein metabolites on the thylakoid membrane and a decrease in the proton gradient, and hence on the effect on AT synthesis. 


\section{Table 1}

Influence of white matter damage on the ratio of the fluorescence spectra of the leaves of the "Orzu" variety of cotton at wavelengths of 690 and $732 \mathrm{~nm}$ and the ratio of the maximum level of fluorescence (Fp) to the ratio of the stationary index of fluorescence intensity (Fo) ( $\mathrm{P}=\mathrm{Fp}-\mathrm{Fo} / \mathrm{Fp})$.

\begin{tabular}{|c|c|c|}
\hline $\begin{array}{c}\text { Experiment options } \\
\text { (cotton plants) }\end{array}$ & $\mathrm{I}_{690} / \mathrm{I}_{732}$ & $\mathrm{P}=\mathrm{F}_{\mathrm{p}}-\mathrm{F}_{\mathrm{o}} / \mathrm{F}_{\mathrm{p}}$ \\
\hline Control & $1,943 \pm 0,185$ & $0,819 \pm 0,112$ \\
\hline $\begin{array}{c}\text { the pest was moderately } \\
\text { prevalent and signs of } \\
\text { damage were less } \\
\text { noticeable }\end{array}$ & $2,495 \pm 0,239$ & $0,617 \pm 0,124$ \\
\hline $\begin{array}{c}\text { The pest is strongly } \\
\text { distributed and the leaves } \\
\text { clearly visible signs of } \\
\text { damage }\end{array}$ & $2,942 \pm 0,264$ & $0,562 \pm 0,084$ \\
\hline
\end{tabular}

Note: The mean magnitudes of the 6 spectra are given by the mean deviations. The reliability probability interval of the mean values is not less than $95 \%(P \leq 0.05)$.

The kinetics of fluorescence, which reflects the processes occurring in ETC, also vary depending on the degree of damage to the plant. In this case, the decrease in the (FpFo)/Fp index depends on the degree of damage to the plant, both for the $690 \mathrm{~nm}$ wavelength kinetics and for the $732 \mathrm{~nm}$ wavelength kinetics. This figure reaches $32 \%$ when half of the plants are damaged and $46 \%$ when all are damaged. This suggests that protein metabolites affect both the photosystems of the cotton photosynthetic apparatus itself and ETC.

The kinetic kinetics of induction curves and changes in the luminescence spectra of chlorophyll are due to disturbances in the activity of ETC and in the structural structure of long-wavelength forms of chlorophyllprotein complexes of plants $\mathrm{PH}[3$, p. 188; 5, pp. 263-272; 6, pp. 123-134]. 
Doi: https://doi.org/10.37547/tajiir/Volume02Issue08-07

Thus, it can be concluded from the above that when the "Orzu" cotton variety is infested electron-transport chain of the photosynthetic apparatus is blocked.

We measured the LIF of a cotton leaf extracted from controlled and QN-treated seeds throughout the growing season. This allowed us to determine the relationship with algae, the long-wave native forms of cotton chlorophyll are disrupted and the between changes in fluorescence parameters over a long period of time ( 8 weeks) depending on the number of insects on the leaves of plants in the two groups. The results are shown in Figure 3.6. For comparison, we have shown Figure 3.1 again in this figure (Figure 3.6A).

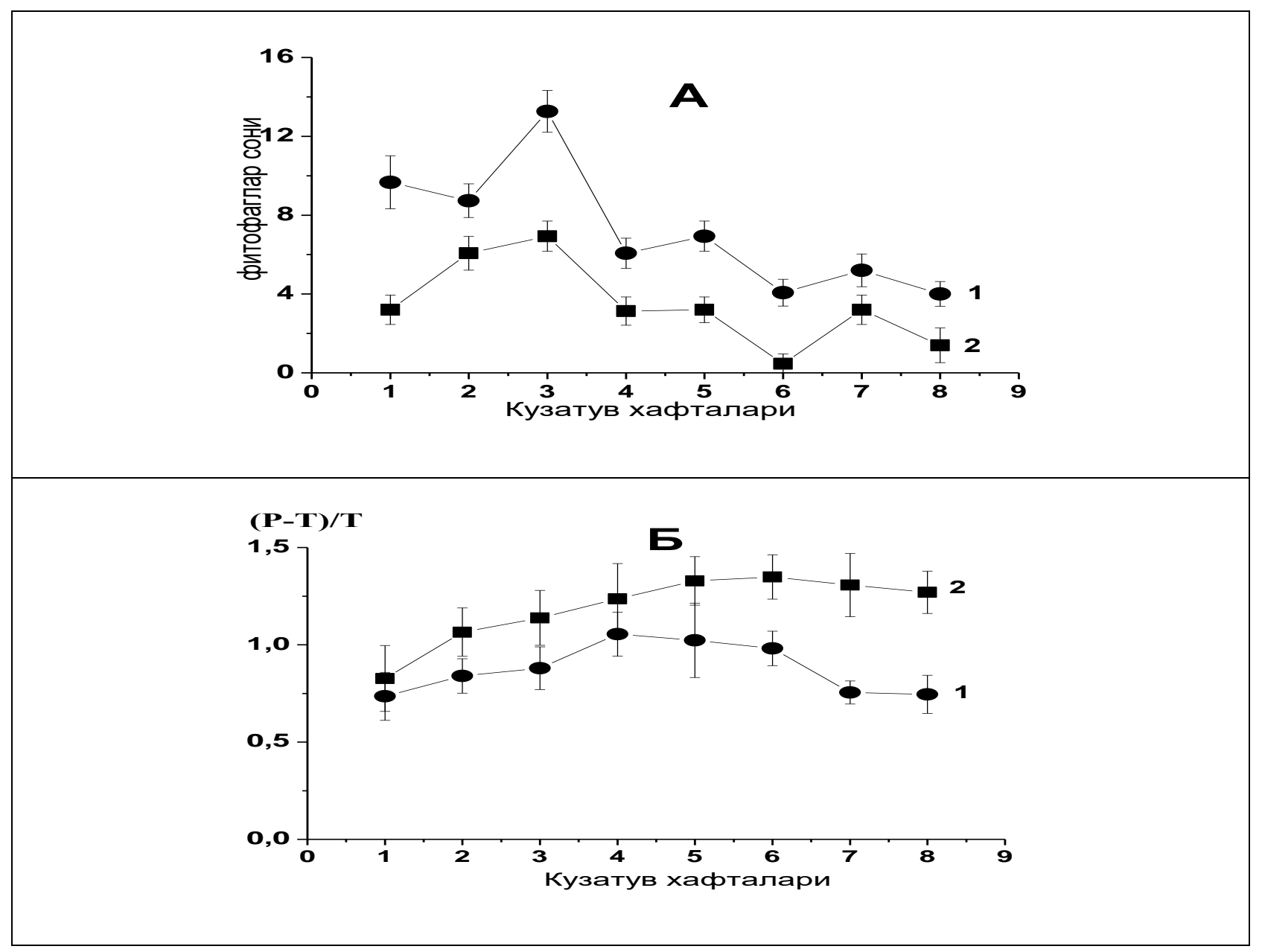




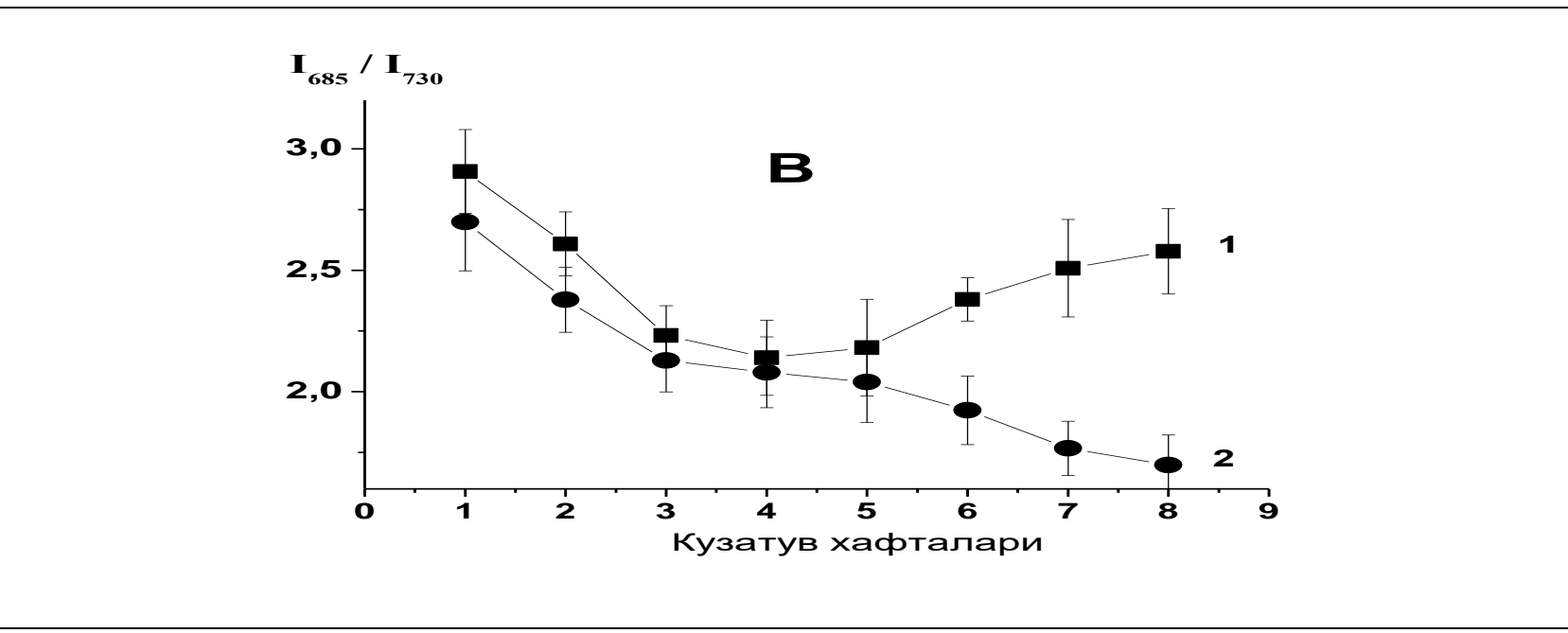

Figure 1. Influence of QN treatment before sowing on seeds of "Orzu" cotton variety on changes in the number ( $A)$ of greenhouse effluents and LIF ( $B$ and V) indicators at different stages of vegetation.

Note: 1 - controlled plants, 2 - plants grown from QN treated seeds. The mean magnitudes of the changes in LIF values obtained from the 6 spectra were given with mean deviations $(P \leq 0.05)$.

As shown in Figure 1.A, the number of insects in controlled plants decreases over time, as in plants grown from QN-treated seeds, due to the activation of defense mechanisms that respond to plant damage by insects. Moreover, these protective mechanisms are more clearly reflected in plants grown from QN-treated seeds.

As the number of algae in plants increases, the efficiency of $\mathrm{PH}$ work decreases, which indicates that the value of the (Fp-Fo)/Fp ratio was small in all periods of our observations and also sharply decreased from week 4 of our observations. These figures indicate the failure of the $\mathrm{PH}$ electronic transport chain (ETC).

A sharp change in the ratio of fluorescence intensities at 685 and $730 \mathrm{~nm}$ wavelengths, as mentioned above, indicates either a decrease in its number due to a violation of the I photosystem (I FS) or a violation of the phosphorylation of the light-collecting complex.

When the seeds were treated with QN before sowing, the coefficients (Fp-Fo)/Fp and $1685 / 1730$ had a constant value from week 4 of our observations, which corresponds to the luminescence of the pest-infested leaves of cotton. This evidence suggests that photostimulation of seeds significantly inhibits the inhibition of photosynthetic apparatus activity of plant leaves associated with disruption of long-wavelength forms of chlorophyll and blockade of cotton PH, ETC under unfavorable phytopathogenic conditions. As a result of QN treatment of seeds, the distribution of algae in plants decreases, while the activity of photosynthetic apparatus, on the contrary, increases. This means that phytochrome 
photo-conversion has a specific effect on the photosynthetic apparatus.

Thus, the results of the above studies allow us to conclude that when the seeds are treated with QN, by activating the plant's defense mechanisms, the leaf of the cotton variety "Orzu" prevents the occurrence of harmful effects of algae at the level of PH activity.
Figure 2 shows the spectra of fluorescence of the seed of the cotton variety "Orzu" at different stages of development. As can be seen in the figure, the spectra of both photosystem I $(732 \mathrm{~nm})$ and photosystem II (685 nm) in the luminescence fields change slightly during seed processing.

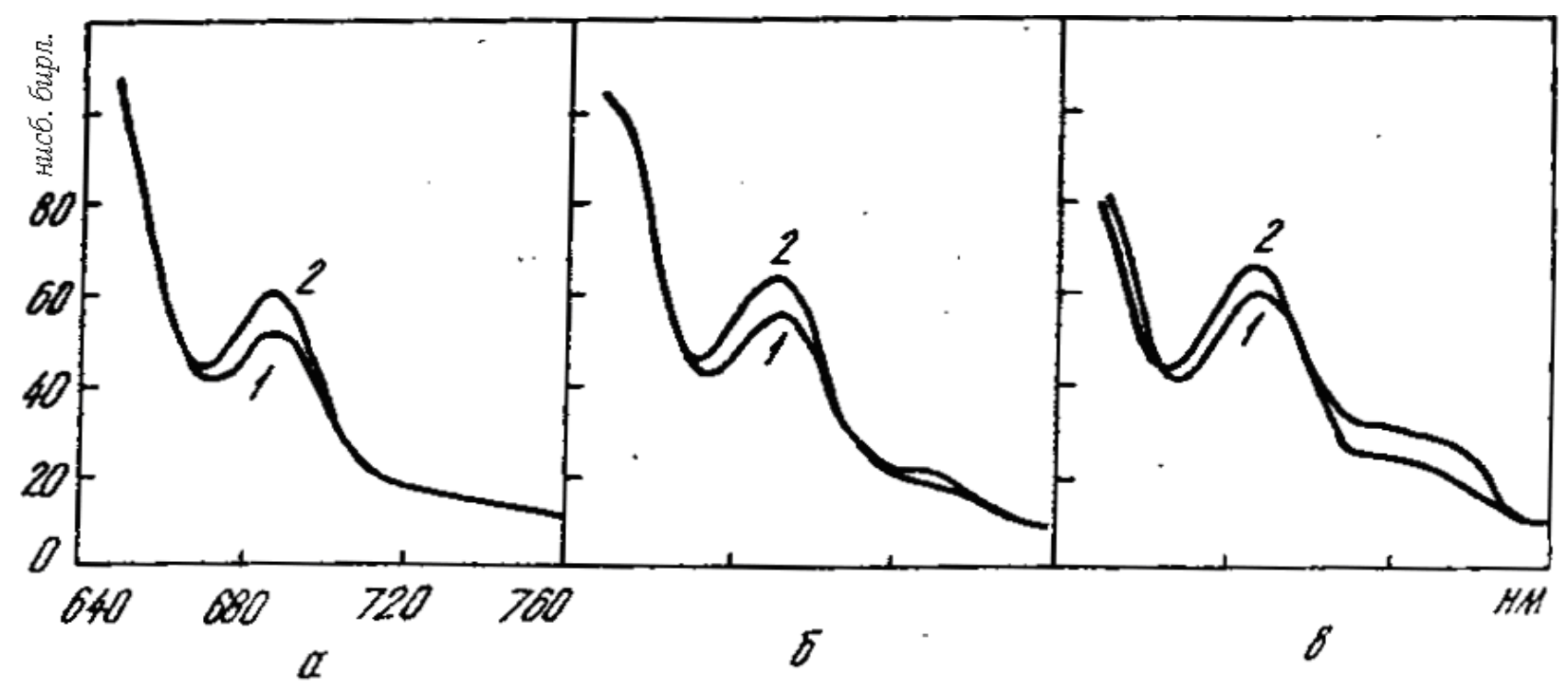

Note: Measured $24 \mathrm{~h}(\mathrm{a}), 48 \mathrm{~h}$ (b) and $72 \mathrm{~h}$ (c) after leaf opening.

Figure 2. Typical spectra of laser-induced fluorescence of the seed of the cotton variety "Orzu" grown from seeds of intact (1) and irradiated with red light (2).

However, it should also be noted that the effect of light on I FS was found to be much weaker than on FS II and delayed over time relative to FS II. When the seeds were irradiated with QN, the fluorescence intensity of the leaves at $685 \mathrm{~nm}$ increased by an average of $27 \%$ after 24 hours compared to the control, and at $732 \mathrm{~nm}$ it increased by $13 \%$ only
72 hours after germination. Presumably, this is due to the later formation of FS I than FS II, and the results of research on the effects of QN on plants [8] suggest that its stimulatory effect decreases over time. When we analyzed the spectra of laser-induced fluorescence (LIFC) of chlorophyll, we found that the stimulating effect of QN did not affect the 
formation of the light-collecting complex (LFC). This is because no difference was observed between the spectra of plant leaves grown from irradiated and non-irradiated seeds with QN at wavelengths around $700 \mathrm{~nm}$ $( \pm 20 \mathrm{~nm})$.

Table 2 shows the results on the effect of red light treatment on seeds on the ratio and spectral-kinetic parameters of the leaf surface $24,48,72$ hours after the opening of the leaf blade.
Analysis of the slow-acting fluorescence induction curve (Table 2) shows that the activity of the photosynthetic apparatus (PH) electron transport chain (ETC) increases significantly when seeds are irradiated, especially in the early stages of leaf development. In controlled plants, the induction curves began to be corrected on the first day after leaf opening - (R-T) / T <1 ( $R$ is the maximum intensity of the induction curve, $T$ is the intensity of the stationary level) indicating the absence of this formed electron transport chain.

Table 2

Influence of red light treatment on seeds on the surface ratio and spectral-kinetic parameters of the leaves of the seed pod 24, 48, 72 hours after the opening of the leaf plate of the cotton variety "Orzu"

\begin{tabular}{|c|c|c|c|c|c|c|}
\hline \multirow[t]{2}{*}{$\begin{array}{l}\text { Time, } \\
\text { hour }\end{array}$} & \multicolumn{2}{|c|}{ Control } & \multicolumn{2}{|c|}{ Irradiation with QN } & \multirow[t]{2}{*}{$\mathrm{I}_{685 \mathrm{KH}} / \mathrm{I}_{685 \mathrm{H}}$} & \multirow[t]{2}{*}{$\mathrm{I}_{732 \mathrm{KH}} / \mathrm{I}_{732 \mathrm{H}}$} \\
\hline & $(\mathrm{P}-\mathrm{T}) / \mathrm{T}$ & $\mathbf{S}_{1} / \mathbf{S}_{24}$ & $(\mathrm{P}-\mathrm{T}) / \mathrm{T}$ & $\mathbf{S}_{1} / \mathbf{S}_{24}$ & & \\
\hline 24 & $0,17 \pm 0,06$ & 1 & $4,02 \pm 0,31$ & 1 & $1,27 \pm 0,11$ & $1,02 \pm 0,09$ \\
\hline 48 & $4,07 \pm 0,53$ & $2,31 \pm 0,05$ & $5,34 \pm 0,27$ & $2,97 \pm 0,23$ & $1,17 \pm 0,09$ & $1,11 \pm 0,12$ \\
\hline 72 & $3,51 \pm 0,31$ & $4,05 \pm 0,27$ & $3,06 \pm 0,19$ & $5,06 \pm 0,35$ & $1,09 \pm 0,07$ & $1,13 \pm 0,06$ \\
\hline
\end{tabular}

Note: St is the surface area of the leaf at the time of measurement: $t=24,48,72 \mathrm{~s}$; S24 is the surface of the leaf 24 hours after the opening of the cotton seed; $1685 \mathrm{H}, 1732 \mathrm{H}$ fluorescence intensity at 685 and $732 \mathrm{~nm}$ wavelengths under control; $1685 \mathrm{KH}, 1732$ ҚН fluorescence intensity of 685 and $732 \mathrm{~nm}$ wavelength of plant leaf grown from irradiated seeds; $R$ is the maximum intensity of the induction curve, $T$ is the intensity of the stationary level. The reliability probability interval of the mean values is not less than $95 \%(P \leq 0.05)$. 
It is known that the efficiency of electron transport in cells during cell division is much lower than in differentiated and mature cells, which means that when seeds are irradiated, the process of cell differentiation is accelerated and, as a result, the formation of photosynthetic apparatus is accelerated [41]. ontogeny, the intensity of photosynthesis increases rapidly per unit area, reaches a maximum in $40-70 \%$ of the area, and then gradually decreases [25].

According to the data on the amount of pigments (Table 3.4), the number of CV increases when the seeds are treated with red light, and the CA / CV ratio decreases due to this. Therefore, the amount of light-collecting complex increases with respect to FS I and FS II [41].

The formation of $a$ and $b$ chlorophylls in the photo-regene phase of proto-chlorophyll, the synthesis of chlorophyll and the integration of chlorophyll-binding polypeptides of pigmentprotein complexes, the control of light stabilization of a protein such as pigment in
Our hypothesis of faster leaf development is also confirmed by the results we obtained when we measured its surface, i.e. in plants irradiated with QN, the leaf surface increases by $25-30 \%$. This evidence is important because it is known that in leaf

these complexes are generalized as a model [41]. For example, the use of rays of different spectral lengths not only induces the biosynthesis of photosynthetic enzymes, the formation of chlorophyll and carotenoids [106], the role of phytochrome in the activation of LFC accumulation associated with FS II in leaves [126], but also photoregulatory systems that control growth, deetiolation and photosynthesis also allowed to determine its role in the management of the relationship between. Our results are fully consistent with modern views on the possibility of controlling plant growth and development, photosynthetic pigment synthesis, and photosystem formation using phytochrome.

\section{Table 3}

\section{Effect of red light (QN) treatment on seeds on the amount of pigments ( $\mathrm{mg}$ / g wet mass) in the leaves of "Orzu" cotton variety}

\begin{tabular}{|c|c|c|}
\hline Pigment & Control & QN \\
\hline Chlorophyll $a$ & $1,521 \pm 0,053$ & $1,575 \pm 0,045$ \\
\hline $\begin{array}{c}\text { Chlorophyll } b \\
\text { and } b \text { are the sum of } \\
\text { chlorophylls }\end{array}$ & $0,552 \pm 0,016$ & $0,742 \pm 0,037 \mid$ \\
\hline
\end{tabular}




\begin{tabular}{|c|c|c|}
\hline The sum of carotenoids & $0,462 \pm 0,015$ & $0,475 \pm 0,019$ \\
\hline Chlorophyll $a / b$ & $2,755 \pm 0,069$ & $2,123 \pm 0,082$ \\
\hline Chlorophylls / carotenoids & $4,487 \pm 0,084$ & $4,878 \pm 0,101$ \\
\hline
\end{tabular}

Note: Average values of the number of pigments measured in at least 15 leaves \pm standard deviations. The reliability probability interval of the mean values is not less than $95 \%(P \leq$ 0.05).

However, according to the results of our study, it is impossible to give a definite answer as to where phytochrome affects the formation of $\mathrm{PH}$, because the photosynthetic activity of a leaf depends not only on the number of chlorophylls in it, but also on all ontogenetic changes of the leaf. Leaf growth, tissue differentiation, and aging are accompanied by continuous changes in the structure and functional state of all elements of the $\mathrm{PH}$. As a result, the occurrence parameters of photosynthetic function change continuously and this can be reflected in the LIF spectral-kinetic parameters of the leaves.

However, we hypothesized that the stimulating effect of QN was not related to its direct effect on chlorophyll synthesis, but to its effect at the level of the whole organism. As previously shown [13], the spectrum of action of phytochrome is very wide, which indicates the activation of processes in the leaf, where it affects, more precisely at the genome level.

Thus, QN treatment suggests that it accelerates the formation of the photosynthetic apparatus (PH) in the early stages of ontogeny, and that this acceleration can compensate for the damage of this apparatus by pest-insect-organisms. In addition, irradiation with QN results in rapid enlargement of the leaf plate surface.

\section{CONCLUSION}

Summarizing the data on the increase of plant resistance to pests as a result of treatment of seeds with red light and low-frequency electromagnetic field, it can be concluded that the increase in this resistance is due to various mechanisms. We identified 3 of these mechanisms: 1 - changes in the anatomical and morphological parameters of the leaf, 2 - an increase in the amount of phytoalexins, 3 - the rapid formation of the photosynthetic apparatus and the maintenance of its functional activity under conditions of increased phytopathogenic state.

When seeds are treated with red light before sowing, the rate of formation of the cotton photosynthetic apparatus increases during ontogeny, which is a factor that helps maintain the functional activity of the photosynthetic apparatus $(\mathrm{PH})$ under adverse entomopathogenic conditions. 


\section{REFERENCES}

1. Veselovsky V.A., Veselova T.V. (1990) Luminescence of plants. - Moscow. Nauka. - p. 176.

2. Kimsanbaev Kh.Kh., Zakhidov FM, Kadyrov A. (1997) Whiteflies and their entomophages. Tashkent: Ministry of Agriculture and Water Resources. - p. 43.

3. Korneev D.Y. (2002) Informational possibilities of the method of chlorophyll fluorescence induction. - Kiev. Alterpress. - p. 188.

4. Kreslavsky V. D. (2010) Regulation of stress resistance of the photosynthetic apparatus by inductors of various nature: Author's abstract. dis. Doctor of Biological Sciences. - Pushchino. IPPB RAS. - p. 40.

5. Levin I.M., Klochkova M.P., Radomyslskaya T.M. (1988) Accounting for luminescence in optical experiments on plant leaves // Optics and Spectroscopy. - Moscow. No. 2. - pp. 263-272.

6. Lukin Yu.A., Agishev V.S., Bernikov A.D., Mergelyan O.S. (1989) Investigation of the spectral-kinetic characteristics of laser-induced plant fluorescence // Atmospheric Optics. - Moscow. Vol. 2, No. 5. - pp. 123-134. 